\title{
Editorial
}

\section{Ampliação de Visibilidade}

Temos a grata satisfação de entregar o primeiro fascículo do Volume 17 (Ano 2001) de Psicologia: Teoria e Pesqui$s a$, e assim continuar contribuindo para a difusão da produção representativa da pesquisa em psicologia. É com satisfação que também comunicamos sua disponibilização, junto com uma coleção selecionada de pouco mais de 50 revistas acadêmicas brasileiras, na biblioteca eletrônica virtual SciELO, Scientific Library Online, um projeto desenvolvido pela FAPESP - Fundação de Amparo à Pesquisa do Estado de São Paulo, em colaboração com a Bireme - o Centro Latino-Americano e Caribenho de Informação sobre as Ciências da Saúde. Além disso, registramos que nossa Revista poderá ser acessada em dois endereços eletrônicos internacionais: eupsi e scirus, sendo o primeiro, uma publicação eletrônica com sede em Évora, Portugal, e que se dedica à difusão de tudo referente ao que acontece nos países de língua portuguesa nas diversas áreas da psicologia.

Nossa expectativa com relação à disponibilização eletrônica é positiva e tal positividade tem por base as informações transmitidas por Lewis Joel Greene (2000), editor do Brazilian Journal of Medical and Biology Research. De acordo com Greene, dois problemas levaram ao desenvolvimento do SciELO: ele surge como resposta às tendências atuais à publicação eletrônica global, e também procurando responder ao "problema da ciência perdida no terceiro mundo", levantado em artigo de W. Wayt Gibbs, publicado em 1995 no Scientific American e referido por Greene. O SciELO visa contribuir para a solução do problema da falta de visibilidade e de acessibilidade enfrentado por muitas revistas brasileiras de qualidade. Assim, ele argumenta que, embora algumas revistas sejam indexadas, como é o caso de Psicologia: Teoria e Pesquisa, "a maioria das revistas brasileiras não está incluída em bases de dados internacionais estabelecidas" e que mesmo as revistas "incluídas em bancos de dados têm enfrentado sérios problemas na distribuição de resumos e separatas em nível mundial." Para Greene, é dentro desse contexto que o SciELO opera uma revolução na editoração de revistas acadêmicas visto "providenciar, enquanto índice, uma solução integrada dos problemas de visibilidade das revistas e ao permitir acessibilidade, colocando gratuitamente artigos completos à disposição dos leitores."

Todavia, a promessa de mais visibilidade para a ciência brasileira através dos meios eletrônicos tem sido recebida por muitos com um certo temor que podemos ver manifesto na forma da pergunta "Qual o futuro das revistas científicas em papel?" É muito cedo ainda para sabermos os efeitos dessa revolução. O que será talvez esclarecido nesse embate entre revista em papel e revista por meio eletrônico é a especificidade de cada uma: a que necessidades distintas elas servem, que vantagens e desvantagens cada uma apresenta para o trabalho do pesquisador? Como instrumento de trabalho do pesquisador não será a revista em papel de leitura mais agradável que o artigo exposto na tela? Não será uma vantagem maior ter uma revista que folhas soltas fáceis de serem extraviadas? Por outro lado, o serviço on line se pensado como um informativo geral talvez não apresente qualquer perigo para as revistas em papel. Muito pelo contrário, sua existência facilita a comunicação científica e leva o usuário a buscar a revista impressa. E isto é o que parece, de fato, estar acontecendo e responde por nossa expectativa positiva.

É também um prazer anunciar que, em virtude de modificação introduzida no artigo nono do Estatuto de Psicologia: Teoria e Pesquisa, a revista passa a contar doravante com um Conselho Editorial Internacional (International Editorial Board), o que seguramente contribui ainda mais para a sua maior visibilidade e projeção internacional. Aos membros do novo Conselho somos muito agradecidos pela gentileza de se disporem a colaborar conosco na árdua tarefa de transformar manuscritos em artigos publicáveis.

\section{No vasto território da psicologia}

Este número apresenta uma série de artigos que bem ilustram a complexidade dos problemas individuais e sociais com a qual os pesquisadores se defrontam, a diversidade de temas e metodologias de pesquisa. No início, a reflexão sobre a influência dos meios de comunicação de massa na produção de nossos modos de existência e a manutenção do espírito atento na busca de formas de vida sem violências é o que nos solicita o artigo de Cecília Coimbra, "Mídia e produção de modos de existência”.

O trabalho de Barbieri e Jacquemin, "Perfil psicológico de migrantes através da forma IRF do MMPI", revela a cruel relação entre analfabetismo, desemprego e doença mental. A amostra estudada pelos autores foi de 20 homens de baixo nível sócio-econômico, analfabetos, desempregados, com idade média de 40 anos, e dos quais $70 \%$ eram solteiros. Excetuando o aspecto migração, essa amostra aparenta muita semelhança com o perfil traçado pelo Censo Clínico e Psicossocial dos Pacientes Internados na Casa de Saúde Dr. Eiras-Paracambi, realizado nos meses de novembro e dezembro de 2000 pela Secretaria de Estado de Saúde do Rio de Janeiro (Magalhães, 2001). O número de pacientes desse manicômio é de 1494 e no perfil ao qual eles servem de base, a faixa de idade que tem o maior percentual de internados é 40 a 49 anos, com 33\% (homens) e 28,4\% (mulheres). Quanto ao grau de instrução, a percentagem maior é de analfabetos: 49,6\% (homens) e 47,1\% (mulheres). No que toca ao estado civil, de longe a maior pocentagem é de solteiros: 88,6\% (homens) e 73,6\% (mulheres). E, quanto à con- 
dição sócio-econômica, 51,2\% (homens) e 61,3\% (mulheres) constam no quadro como sem renda própria, o que seguramente pode traduzir-se por "desempregados".

A área de Psicologia do Desenvolvimento Humano contribui com três artigos para este número. Em seu "Aspectos cognitivos e comportamentais na média meninice de crianças nascidas pré-termo e com muito baixo peso", Bordin, Linhares e Jorge apontam para a necessidade de estudos longitudinais sobre esse grupo de risco. Por outro lado, temos a constatação de que diferenças de gênero e o contexto de acontecimento do brinquedo são estruturantes dessa atividade apresentada no artigo de De Conti e Sperb, "O brinquedo de pré-escolares: um espaço de ressignificação cultural”. E, no artigo "Concepções de educadoras sobre a adaptação de bebês à creche", Rapoport e Piccinini apresentam os resultados que obtiveram por meio da análise de conteúdo de respostas de educadoras a um questionário aberto sobre a adaptação de bebês ao modo de vida da creche.

As várias nuances da complexa questão do comprometimento afetivo de empregados com as organizações nas quais trabalham (e as contradições implicadas em tal valoração) são apresentadas no artigo de Tamayo e colaboradores, "Prioridades axiológicas e comprometimento organizacional". Por sua vez, a formação profissional de estudantes de medicina é o foco do artigo de Dejano Sobral, "Características do Inventário de Raciocínio Diagnóstico de Bordage, Grant e Marsden”. Adaptado para estudantes de psicologia, o instrumento utilizado por Sobral poderá encontrar um lugar na supervisão de estágios em psicoterapia e psicodiagnóstico.
"Um caso de transtorno de personalidade borderline atendido em Psicoterapia Dinâmica Breve" é o artigo apresentado por Cunha e Azevedo, o qual traz uma contribuição para o desenvolvimento da escrita de artigos da categoria "estudo de caso". Bunchaft e Vasconcellos relatam ter obtido em seu trabalho, "Padronização do Teste Desiderativo no contexto da Análise Transacional: resultados preliminares", resultados que divergem daqueles obtidos por Ocampo em investigações semelhantes em Buenos Aires.

$\mathrm{O}$ artigo de Colom e Flores-Mendoza é uma revisão de trabalhos experimentais sobre o conceito de "memória de trabalho" e suas conexões com outros conceitos cognitivos, e tem o longo título de "Inteligência e memória de trabalho: a relação entre fator $g$, complexidade cognitiva e capacidade de processamento".

E, por fim, a auspiciosa notícia trazida por Ileno Izidio Costa sobre a escolha de Brasília como local para a realização da Sexta Conferência Internacional Sobre Filosofia, Psiquiatria e Psicologia, em Julho de 2003, com o tema "Ética, linguagem e sofrimento". Essa boa nova é seguida de dois anuncios convidando pesquisadores a submeterem trabalhos sobre temas de saúde mental e ética psiquiátrica.

\section{Referências}

Greene, L.J. (2000). Mais visibilidade para a ciência brasileira. Pesquisa FAPESP, setembro, p. 7.

Magalhães, M. (2001, $1^{\mathrm{o}}$ julho). Censo revela abandono em manicômio. Folha de São Paulo, p. C 5.

Norberto Abreu e Silva Neto, Editor

\title{
Errata
}

\author{
No Volume 16, número 3, na página vii, relação de Con- \\ sultores ad hoc, \\ onde se lê: \\ Cristina Maria de Souza Brito Dias \\ Universidade Federal de Pernambuco \\ leia-se: \\ Cristina Maria de Souza Brito Dias \\ Universidade Católica de Pernambuco
}

